\title{
DE QUE ESCRITA ESTAMOS FALANDO? CONCEPÇÃO DE ESCRITA NA BNCC
}

\author{
Maria Célia do Nascimento* \\ Denise Lino de Araújo**
}

Resumo

\begin{abstract}
A Base Nacional Comum Curricular (doravante BNCC) é um documento parametrizador, de caráter normativo, que deve ser usado na elaboração dos currículos das escolas públicas e privadas do Brasil. Assim, considerando a sua relevância para a educação, o presente artigo, decorrente de pesquisa mais ampla, de natureza quali-quantitativa e do tipo documental, tem como objetivo geral investigar as orientaçóes teóricas presentes na BNCC do Ensino Fundamental sobre o ensino de escrita. Em relação aos objetivos específicos, temos: (1) indicar a(s) concepção(ões) de escrita presentes na BNCC e (2) contribuir para a compreensão desse documento parametrizador. Para realizar a análise, apoiamo-nos nas contribuiçôes de Kato (1986), Kock (2005), Koch e Elias (2009), Sautchuk (2003), entre outros. Os resultados denotam que a BNCC apresenta a escrita como uma atividade de interação.
\end{abstract}

Palavras-chave: BNCC. Ensino Fundamental. Escrita. Interação.

\section{INTRODUÇÃo}

Os documentos parametrizadores são elaborados tendo "como finalidade direcionar e apresentar caminhos a serem seguidos no ensino como um todo. Configuram-se como ponto de partida para o trabalho docente nas mais variadas disciplinas escolares, funcionando como norte para as atividades a serem realizadas em sala de aula" (SOUZA; FERRAZ; COSTA, 2014, p. 2). Desse modo, a BNCC é um documento parametrizador que "indica conhecimentos e competências que se espera que todos os estudantes desenvolvam ao longo da escolaridade" (BRASIL, 2017, p. 7).

A construção da BNCC, iniciada no ano de 2015, já era prevista na LDB no 9.394/96. O documento referente ao Ensino Fundamental teve as suas duas primeiras versões finalizadas em 2016 e a terceira versão concluída em abril de 2017 e homologada pelo MEC, após a aprovação do Conselho Nacional de Educação (CNE), em dezembro do mesmo ano. A homologação resultou numa nova versão da BNCC, decorrente da análise feita pelo CNE na terceira versão do documento, a qual se constitui no corpus $^{1}$ desta pesquisa.

A pesquisa ${ }^{2}$, da qual o presente artigo se desdobra, se caracteriza como de natureza quali-quantitativa. É qualitativa porque analisamos a BNCC com a finalidade de compreendê-la, investigando as suas particularidades referentes à escrita no Ensino Fundamental, e quantitativa porque na análise dos dados apresentamos levantamentos das ocorrências de termos e conceitos relativos à escrita localizados nesse documento. Sobre a pesquisa quali-quantitativa,

Mestranda do Programa de Pós-graduação em Linguagem e Ensino da Universidade Federal de Campina Grande. E-mail: <celia.eter@gmail.com>.

Doutora em Educação. Professora da Unidade Acadêmica de Letras e do Programa de Pós-Graduaçâo em Linguagem e Ensino da Universidade Federal de Campina Grande. E-mail: <deniselinoaraujo@gmail.com>.

Instrumento: R. Est. Pesq. Educ., Juiz de Fora, v. 20, n. 1, jan./jun. 2018 
Ferreira e Lino de Araújo (2013, p. 2) asseguram que ela "privilegia a interpretação dos dados, o entendimento dos fenômenos e processos socialmente situados num contexto, através da busca de um equilíbrio entre as perspectivas de pesquisa qualitativa e quantitativa”.

Em relação ao procedimento utilizado para a geração dos dados, a pesquisa se classifica como documental, esta definida por Sá-Silva, Almeida e Guindani (2009, p. 5) como "um procedimento que se utiliza de métodos e técnicas para a apreensão, compreensão e análise de documentos dos mais variados tipos". Neste tipo de pesquisa, os documentos são utilizados "como fontes de informaçôes, indicaçóes e esclarecimentos que trazem seu conteúdo para elucidar determinadas questóes e servir de prova para outras, de acordo com o interesse do pesquisador".

Le Goff (1997) concebe o documento como um monumento, o que exige uma avaliação minuciosa, tendo em vista que semelhante a um monumento, a figura apresentada no documento pode não ser verídica, pois "um monumento é em primeiro lugar uma roupagem, uma aparência enganadora, uma montagem. É preciso começar por desmontar, demolir esta montagem, desestruturar esta construção e analisar as condições de produção dos documentos-monumentos” (p. 104).

Sendo assim, considerando a BNCC como um monumento, temos como objetivo geral na pesquisa da qual esse artigo decorre investigar as orientaçóes teóricas apresentadas na BNCC referente à escrita no componente Língua Portuguesa nos Anos Finais do Ensino Fundamental. Em relação aos objetivos específicos, temos: (1) indicar a(s) concepção(óes) teórica(s) de escrita presentes na BNCC e (2) contribuir para a compreensão desse documento parametrizador.

Diante disso, o presente artigo está organizado em quatro partes, a saber: esta introdução; os fundamentos teóricos; a análise dos dados e algumas consideraçôes sobre a análise realizada.

\section{As CONCEPÇÓES TEÓRICAS DE ESCRITA}

Segundo Koch e Elias (2009), ao longo do tempo, a escrita vem se constituindo como um produto sócio-histórico-cultural. No entanto, ela também é compreendida como inspiração, atividade para poucos privilegiados, expressão do pensamento, domínio das regras gramaticais. Essa pluralidade de conceitos indica que a compreensão da escrita envolve aspectos de natureza variada, podendo ser "linguística, cognitiva, pragmática, sócio-histórica e cultural” (KOCH; ELIAS, 2009, p. 31). Desse modo, sua definição está associada a uma concepção de linguagem, texto e sujeito. A partir disso, a escrita pode ser compreendida segundo três concepções, as quais têm como foco a língua, o escritor ou a interação.

$\mathrm{Na}$ concepção de escrita com foco na língua, o texto é concebido como o produto da codificação feita pelo escritor e será decodificado pelo leitor. Para isso, o escritor e o leitor só precisam conhecer o código utilizado. Nessa concepção, não há informações implícitas, "tudo está dito no dito, ou em outras palavras, o que está escrito é o que deve ser entendido" (KOCH; ELIAS, 2009, p. 33). Subjacente a essa visão de escrita, encontra-se uma concepção de linguagem como um sistema pronto, cabendo ao escritor, sujeito determinado pelo sistema, apropriar-se dele e de suas regras.

$\mathrm{Na}$ concepção de escrita com foco no escritor, o texto é considerado o produto do pensamento do autor, o qual constrói uma representação mental, transpóe para o papel e espera que ela seja compreendida pelo leitor do mesmo modo que a imaginou. Assim, o leitor exerce um papel essencialmente passivo ( $\mathrm{KOCH}, 2005)$, tendo suas experiências e conhecimentos desconsiderados. A essa concepção de escrita subjaz uma compreensão de linguagem enquanto expressão do pensamento do autor, sendo este o senhor absoluto de seus atos e seu dizer. 
A concepção de escrita com foco na interação é considerada como produção textual, exigindo do escritor a ativação de conhecimentos e a mobilização de estratégias. $O$ autor pensa no que vai escrever considerando o seu leitor. Nesta concepção, o escritor precisa conhecer o leitor, organizar as ideias e revisar a escrita ao longo do processo. Com isso o sentido do texto resulta da interaçáo entre os interlocutores, vistos como sujeitos ativos que são construídos dialogicamente no texto.

De acordo com esta última concepção, a escrita se torna uma atividade interativa altamente complexa de produçáo de sentidos, que se realiza com base nos elementos linguísticos presentes na superfície do texto e na sua forma organizacional. Além disso, requer a mobilização de um amplo conjunto de conhecimentos e sua reconstrução no evento comunicativo $(\mathrm{KOCH}$, 2005). Logo, o sentido do texto é resultado da interação entre os sujeitos e não apenas do uso do código ou das intenções do escritor.

A escrita, enquanto uma atividade de interação, exige do escritor a mobilização de estratégias durante a produção do texto, tais como: seleção e organização das ideias, balanceamento entre informaçóes explícitas e implícitas e revisão da escrita ao longo do processo, guiada pelo objetivo da produção e também pela interação estabelecida entre leitor e escritor (KOCH; ELIAS, 2009).

Além dessas estratégias, para produzir um bom tex to, é preciso que o escritor ative alguns conhecimentos armazenados na memória. De acordo com Koch e Elias (2009) e Koch (2005), o autor ativa o conhecimento linguístico, enciclopédico, de textos e os conhecimentos sociointeracionais.

O conhecimento linguistico se refere ao conhecimento da ortografia, da gramática e do léxico da língua. É responsável pela organização linguística na superfície do texto, pelos elementos de coesão, pela escolha lexical, dentre outros aspectos que contribuem para a produçáo e compreensão do texto, além de construir uma imagem positiva do escritor, tendo em vista que demonstra seu esforço para que o texto cumpra sua função comunicativa de forma exitosa, sendo aceito e entendido pelo leitor.

$\mathrm{O}$ conhecimento enciclopédico consiste nos conhecimentos que o escritor possui sobre as coisas do mundo, é adquirido em experiências vivenciadas e armazenado na memória.

O conhecimento de textos se refere a modelos que o escritor possui sobre práticas comunicativas configuradas em textos, considerando os elementos composicionais e os aspectos de conteúdo, função e suporte de veiculação. Esse tipo de conhecimento também está relacionado com o uso da intertextualidade, pois a escrita "é uma atividade que exige a retomada de outros textos, explícita ou implicitamente, dependendo do propósito da comunicação" (KOCH; ELIAS, 2009, p. 44).

$\mathrm{O}$ conhecimento sociointeracional refere-se a modelos cognitivos que o escritor possui sobre práticas interacionais diversas, constituídas histórica e culturalmente. Com base nesses conhecimentos, o autor realiza diversas ações enquanto escreve, tais como: configurar na escrita a sua intenção, permitindo ao leitor reconhecê-la, estabelecer a quantidade de informação necessária no texto, selecionar a variante linguística e o gênero textual adequado à situação sociocomunicativa concreta.

Com base nessa visão sociocognitiva sobre a produção textual, empreendemos a análise de dados, conforme será apresentado na próxima seção.

\section{A ESCRIta NA BNCC: ANÁlise dos DADOS}

Segundo Gil (2008), a análise de um documento é constituída por três fases: pré-análise, exploração do material e tratamento dos dados. A pré-análise referese à escolha do documento; a exploração é a fase de codificação, envolvendo o recorte das unidades e escolha 
das categorias analíticas e o tratamento dos dados é a fase de interpretá-los e torná-los significativos, tendo como subsídio os fundamentos teóricos.

Relacionando a pesquisa às fases da análise documental postas por Gil (2008), esclarecemos que na fase de pré-análise escolhemos a BNCC como objeto de análise.

$\mathrm{Na}$ etapa de exploração do material fizemos o recorte das unidades da BNCC que constituem o corpus da investigação, as quais estão expostas no quadro a seguir:

\begin{tabular}{|c|c|}
\hline UNIDADES DE BNCC & PÁGINAS EM QUE AS UNIDADES SE LOCALIZAM \\
\hline 4. A etapa do Ensino Fundamental & 53 a 58 \\
\hline 4.1 A área de Linguagens & 59 a 62 \\
\hline $\begin{array}{c}\text { 4.1.1 Língua Portuguesa (Introdução) } \\
\text { 4.1.1.2 Língua Portuguesa no Ensino } \\
\text { Fundamental - Anos Finais }\end{array}$ & 63 a 66 \\
\hline
\end{tabular}

Quadro 1- Unidades da BNCC: recorte do corpus de investigação

Fonte: Elaborado pelas autoras (2017), de acordo com o sumário da BNCC (BRASIL, 2017).

Para selecionar as categorias analíticas, responsáveis pela geração dos dados, foi necessário fazer a "(des)montagem" (cf. LE GOFF, 1997) teórica do documento. Para isso, seguimos o percurso metodológico desenvolvido por Nascimento e Lino Araújo (2017), assim, fizemos leituras das unidades que recortamos da BNCC, de modo analítico e interpretativo, observando os indícios linguísticos, ou seja, a ocorrência de palavras e conceitos referentes à escrita. Durante as leituras direcionamos a nossa atenção para: (I) a presença (quantidade) do termo "escrita"; (II) os conceitos explícitos (referentes aos termos) e; (III) os conceitos implícitos (referentes aos termos) apresentados no documento.

No processo de análise da BNCC, essa observação dos termos é uma etapa relevante porque pode indicar as concepções teóricas que subsidiam o documento, o qual não indica referências. Sendo assim, conforme assinalam Nascimento e Lino de Araújo (2017, p. 18), a "recorrência de algumas expressões, aponta para o fato de que a visibilidade de objetos de ensino importantes pode ser reforçada ou apagada".

$\mathrm{Na}$ fase de tratamento dos dados analisamos os dados obtidos através das leituras realizadas durante a etapa de exploração do material. Para desenvolver a análise, tivemos como subsídio as concepçóes teóricas de escrita.

\subsection{A (DES)MONTAgEM TEÓRICA DO DOCUMENTO}

A “(des)montagem” (cf. LE GOFF, 1997) da BNCC aconteceu em três momentos. No primeiro, fizemos uma leitura do documento, observando a ocorrência do termo "escrita", a qual foi localizada 43 vezes nas unidades lidas.

No segundo momento, retornamos à BNCC para averiguar a presença de conceitos que fossem relacionados explicitamente às ocorrências do termo "escrita" contabilizadas na primeira leitura. O resultado obtido está exposto no quadro abaixo: 


\begin{tabular}{|c|c|c|}
\hline $\begin{array}{c}\text { CONCEITOS EXPLÍCITOS RELACIONADOS } \\
\text { AO TERMO ESCRITA }\end{array}$ & $\begin{array}{c}\text { QUANTIDADE DE } \\
\text { OCORRENCIAS }\end{array}$ & PÁGINAS \\
\hline Sistema alfabético & 7 & $54,55,61(2), 64(3)$ \\
\hline Forma de linguagem verbal & 1 & 59 \\
\hline Dimensão da língua & 5 & 63 \\
\hline $\begin{array}{c}\text { Compreende as práticas de produção de textos verbais, } \\
\text { verbo-visuais e multimodais, de diferentes gêneros textuais, } \\
\text { considerando a situação comunicativa, os objetivos visados e } \\
\text { os destinatários do texto. }\end{array}$ & $130,138,146$ \\
\hline $\begin{array}{c}\text { Aprendizagem da codificação de palavras e textos, o } \\
\text { desenvolvimento de habilidades para produzir textos com } \\
\text { coerência, coesão e adequado nível de informatividade. }\end{array}$ & 1 & 64 \\
\hline Bem cultural da humanidade & 2 & 66 \\
\hline Eixo & $\mathbf{1 8}$ & $115(2)$ \\
\hline Total de ocorrências & 1 & $*$ \\
\hline
\end{tabular}

Quadro 2- Levantamento dos conceitos explícitos relacionados à escrita na BNCC

Fonte: Elaborado pelas autoras (2017)

De acordo com o levantamento apresentado no quadro 2, encontramos dezoito ocorrências do termo "escrita" com conceitos explícitos na BNCC. A primeira definição posta no quadro acima, a de escrita como sistema alfabético, aparece nas partes introdutórias da BNCC, as quais são comuns aos Anos Iniciais e Finais do Ensino Fundamental. Com isso, das sete ocorrências localizadas, quatro se referem aos Anos Iniciais (fase de aquisição da escrita) e três não especificam nenhuma das duas etapas, conforme está exposto no trecho abaixo:

\footnotetext{
Durante os dois primeiros anos, a apropriação do sistema alfabético de escrita ocupa espaço de reflexão especial, sendo as demais linguagens ressignificadas pela alfabetização, inclusive a linguagem oral, corporal e artística (BRASIL, 2017, p. 61, grifo nosso).
}

Segundo o trecho, a escrita está relacionada ao sistema alfabético nos primeiros anos do Ensino Fundamental, etapa em que é vista como a aprendizagem das letras, possibilitando a alfabetização dos alunos, a qual, por sua vez, contribuirá para o desenvolvimento de outras linguagens.

A escrita concebida como uma forma de linguagem verbal tem uma ocorrência presente na introdução do texto da área de Linguagens na BNCC, relacionando as formas de linguagem náo verbal e multimodal. Conforme o trecho a seguir retirado da BNCC:

\footnotetext{
Ao se abordar a linguagem no sistema semiótico, que estuda a significação dos textos que se manifestam em qualquer forma de expressão, podese falar de formas de linguagem: verbal (fala e escrita), não verbal (visual, gestual, corporal, musical) e multimodal (integração de formas verbais e não verbais) (BRASIL, 2017, p. 59, grifos nossos).
}

Logo, podemos compreender que a escrita, constituindo-se numa forma de linguagem verbal, é um lugar para a manifestação dos textos escritos. Nesse sentido, considerando que para a BNCC "os conhecimentos humanos são sempre construídos 
por formas de linguagem" (BRASIL, 2017, p. 59), é notório que a aprendizagem e utilização da escrita são significativas para o desenvolvimento das pessoas.

A única ocorrência de escrita enquanto dimensão da língua está localizada na parte introdutória do componente Língua Portuguesa, como está posto no trecho abaixo:

\begin{abstract}
A lingua tem duas dimensôes: é oral e escrita. Assim, sua aprendizagem considera o contínuo entre oralidade e escrita: na alfabetizaçáo, em que o oral é representado por notaçóes (letras e outros signos), nos usos sociais da língua oral e nos usos sociais da leitura e da escrita - nas práticas de letramento (BRASIL, 2017, p. 63, grifos nossos).
\end{abstract}

De acordo com o trecho acima, a escrita, ao ser categorizada como uma dimensão da língua, deve ser ensinada considerando a sua relação com a oralidade, iniciando na alfabetização e continuando ao longo do Ensino Fundamental, abordando os usos sociais dessas duas dimensões.

Também na introdução do componente Língua Portuguesa na BNCC, localizamos a afirmação que a escrita "compreende as práticas de produção de textos verbais, verbo-visuais e multimodais,[...]” Essa compreensão explica o eixo Escrita no documento, expondo as linguagens abrangidas por ele, como mostrado no seguinte fragmento:

\footnotetext{
O eixo Escrita, por sua vez, compreende as práticas de produção de textos verbais, verbo-visuais e multimodais, de diferentes gêneros textuais, considerando a situaçáo comunicativa, os objetivos visados e os destinatários do texto (BRASIL, 2017, p. 64, grifo do original).
}

Logo, de acordo com o fragmento anterior, o eixo Escrita, além de contemplar as formas de linguagem, também considera a situação, os objetivos e os interlocutores envolvidos na produção. Com isso, podemos considerar a escrita como uma atividade interativa (cf. $\mathrm{KOCH}$; ELIAS, 2009), na qual tanto o escritor quanto o leitor são sujeitos reconhecidos e atuantes.
As outras quatro ocorrências dessa conceituação estão presentes, de forma resumida, na explicaçáo do eixo Escrita nas quatro séries dos Anos Finais, como, por exemplo, no fragmento: "EIXO ESCRITA - Práticas de produção de textos verbais, verbo-visuais e multimodais de diversos gêneros textuais" (BRASIL, 2017, p. 120, destaque da BNCC).

Encontramos a definição de escrita na parte introdutória do componente Língua Portuguesa na BNCC, cujo trecho retirado do documento está exposto abaixo:

A escrita compreende a aprendizagem da codificação de palavras e textos (o domínio do sistema alfabético de escrita), o desenvolvimento de habilidades para produzir textos com coerência, coesão e adequado nível de informatividade (BRASIL, 2017, p. 64).

Segundo a citação acima, a escrita se refere ao conhecimento do código linguístico, compreendido como o domínio do sistema alfabético. Além disso, a escrita compreende as habilidades de produção de textos coerentes, coesos e dotados de informação. Ao expor essa conceituação, a BNCC está considerando os aspectos relacionados à estrutura da língua (como os gramaticais e ortográficos) e os aspectos funcionais (como o nível de informação, o qual precisa ser adequado à finalidade do texto escrito). Logo, através dessa definição de escrita, podemos inferir que a BNCC valoriza a produção ao invés da redação de textos (cf. GERALDI, 2006).

A escrita como bem cultural da humanidade está posta nas competências do componente Língua Portuguesa (elas se referem aos Anos Iniciais e Finais do Ensino Fundamental na BNCC). O documento apresenta dez competências específicas a serem desenvolvidas nessa fase da educação básica - a quarta delas se refere à escrita, a saber: "Valorizar a escrita como bem cultural da humanidade" (BRASIL, 2017, p. 66)

Essa relaçáo de escrita como bem cultural da humanidade denota quão importante ela é (ou deve ser) 
durante essa fase de ensino da educação básica. Com isso, compreendemos que para a BNCC a escrita precisa ser ensinada de modo que o aluno possa ter consciência da sua relevância para a humanidade.

A escrita relacionada apenas ao seu eixo está situada na parte inicial do componente Língua Portuguesa dos Anos Finais do Ensino Fundamental, tendo duas ocorrências na mesma página, conforme mostrado no trecho abaixo:

\begin{abstract}
Também no eixo Escrita, em paralelo com o avanço em estratégias de leitura, as estratégias de produção textual vão se tornando, progressivamente, mais numerosas e complexas. O eixo Conhecimento linguísticos e gramaticais parte dos eixos da Leitura (de textos lidos) e da Escrita (de textos produzidos pelos alunos), ao mesmo tempo em que apoia, colaborando com a compreensão, interpretação e produção de textos (BRASIL, 2017, p. 115, grifos nossos).
\end{abstract}

De acordo com o trecho acima, nos Anos Finais do Ensino Fundamental as atividades do eixo Escrita se tornam mais complexas. Esse aumento no nível de complexidade ocorre em comparação aos Anos Iniciais e as atividades de escrita avançam da aprendizagem do sistema alfabético para a sua utilização na produção de textos. O eixo Escrita também subsidia o eixo Conhecimentos linguísticos e gramaticais e é, ao mesmo tempo, apoiado por ele, uma vez que as atividades gramaticais contribuem para a escrita de textos.

No terceiro momento da (des)montagem, realizamos outra leitura da BNCC visando a localização de conceitos que pudessem ser associados às ocorrências do termo "escrita" localizadas na primeira busca empreendida no documento.

Os conceitos encontrados não estão relacionados diretamente aos termos, de modo que conseguimos associá-los através da observação e compreensão do sentido das palavras que se localizavam próximas a eles nas oraçóes e nos parágrafos. O resultado obtido nessa terceira etapa da (des)montagem está apresentado no quadro a seguir:

\begin{tabular}{|c|c|c|}
\hline CONCEITOS ASSOCIÁVEIS AO TERMO ESCRITA & $\begin{array}{l}\text { QUANTIDADE DE } \\
\text { OCORRENCIAS }\end{array}$ & PÁGINAS \\
\hline $\begin{array}{c}\text { Linguagem que usada socialmente (práticas de } \\
\text { letramento) permite a participação no mundo letrado e a } \\
\text { construção de novas aprendizagens. }\end{array}$ & 2 & 54,63 \\
\hline $\begin{array}{l}\text { Habilidade que pode ser exercitada através dos conteúdos } \\
\text { dos componentes curriculares }\end{array}$ & 1 & 55 \\
\hline Dimensão da língua (relação com a oral/falada) & 12 & $\begin{array}{c}61,63(4), 64,122,130 \\
138,146,147,148\end{array}$ \\
\hline Prática relacionada à análise linguística e gramatical & 7 & $\begin{array}{c}64,65,122,130 \\
138,146,148\end{array}$ \\
\hline Forma de registro de informações e anotações & 2 & 127,129 \\
\hline Língua que possui convenções a serem obedecidas & 1 & 131 \\
\hline Total de ocorrências & 25 & * \\
\hline
\end{tabular}

Quadro 3 - Levantamento conceitos implícitos (associáveis) relacionados à escrita na BNCC

Fonte: Elaborado pelas autoras (2017) 
Conforme exposto no quadro 3, localizamos 25 conceitos que podem ser associados ao termo "escrita". Essas associações são válidas porque foram identificadas através da leitura atenta às marcas linguísticas do documento, visando compreender as construçóes textuais e o sentido que expressam.

Sendo assim, compreendemos a escrita como uma linguagem que usada socialmente (práticas de letramento) permite a participação no mundo letrado e a construção de novas aprendizagens a partir da leitura realizada na explicação sobre a etapa do Ensino Fundamental e na introdução do componente Língua Portuguesa na BNCC. Nas duas ocorrências, percebemos o destaque que o documento faz para os usos sociais da escrita nos eventos de letramento, o que gera novas aprendizagens, conforme exposto abaixo:

Como destacam as DCN, a maior desenvoltura e a maior autonomia nos movimentos e deslocamentos ampliam suas interações com o espaço; a relação com múltiplas linguagens, incluindo os usos sociais da escrita e da matemática, permite a participação no mundo letrado e a construçāo de novas aprendizagens (BRASIL, 2017, p. 54, grifo nosso).

Com base no exemplo, apreendemos que a BNCC valoriza a utilização da escrita nos eventos sociais. Com isso, o ensino dessa dimensão da língua precisa ser vinculado às necessidades reais do aluno, visando tornálo um cidadão funcionalmente letrado, "capaz de fazer uso da linguagem escrita para sua necessidade individual de crescer cognitivamente e para atender às demandas de uma sociedade que prestigia esse tipo de linguagem como um dos instrumentos de comunicação" (KATO, 1986, p. 7).

O entendimento de escrita como uma habilidade que pode ser exercitada através dos conteúdos dos componentes curriculares pôde ser (re)construído a partir da leitura do parecer de $n^{o}$ 11/2010 do CNE presente na BNCC, o qual afirma que "os conteúdos dos diversos componentes curriculares [...], ao descortinarem às crianças o conhecimento do mundo por meio de novos olhares, lhes oferecem oportunidades de exercitar a leitura e a escrita de um modo mais significativo" (BRASIL, 2017, p. 55).

Nesse sentido, os conteúdos do componente Língua Portuguesa podem contribuir para o desenvolvimento da escrita, tendo em vista que o conhecimento das regras gramaticais e a habilidade da leitura, por exemplo, dão suporte à escrita de textos. Logo, os conteúdos dos eixos que organizam esse componente na BNCC, principalmente os que se referem à leitura e ao conhecimento linguístico, possuem um relevante papel no processo de ensino e aprendizagem da escrita.

O conceito de escrita enquanto dimensão da língua foi identificado na introdução da área de Linguagens e no componente Língua Portuguesa da BNCC, trechos em que este documento aborda a aprendizagem e o uso da língua oral e escrita. Uma das ocorrências está exposta no seguinte fragmento: "Para atender a essa multiplicidade de modalidade e usos da língua escrita e da língua oral, e tendo sempre o texto como centro, a BNCC de Língua Portuguesa está organizada em cindo eixos organizadores comuns ao longo do Ensino Fundamental” (BRASIL, 2017, p. 63).

A escrita concebida como uma prática relacionada à análise linguistica e gramatical foi identificada em sete momentos da explicação do eixo Conhecimentos linguísticos e gramaticais, sendo dois situados na introdução do componente Língua Portuguesa, comum aos Anos Iniciais e Finais do Ensino Fundamental, e os demais nas séries finais do mesmo componente. A seguir está exposto um exemplo dessas ocorrências, extraída da BNCC.

O eixo Conhecimentos linguisticos e gramaticais compreende, no Ensino Fundamental - Anos Iniciais, o processo de alfabetização, e se amplia, ao longo do Ensino Fundamental, pelas práticas de análise linguística e gramatical, estreitamente relacionadas com o desenvolvimento produtivo das práticas de oralidade, leitura e escrita (BRASIL, 2017, p. 63, grifos do original). 
Essa relação posta pela BNCC entre escrita e análise linguística e gramatical reforça a afirmação dita anteriormente acerca da relevância dos conteúdos gramaticais para o desenvolvimento da escrita. Como exposto no exemplo acima, nos Anos Iniciais do Ensino Fundamental, os saberes linguísticos estão relacionados à alfabetização, enquanto nos Anos Finais, estão relacionados ao desenvolvimento da prática de escrita, sendo ampliados nessa fase de ensino.

A escrita enquanto forma de registro de informaçóes $e$ anotaçóes foi identificada em dois trechos na BNCC, um deles afirma ser uma habilidade a ser desenvolvida pelos alunos no eixo Oralidade, "registrar as ideias principais durante a escuta de uma apresentação oral, por meio de anotações escritas" (BRASIL, 2017, p. 127).

Essa habilidade denota a relação entre as dimensões escrita e oral da língua, sendo a escrita vista como uma forma de registro da língua oral. É relevante assinalar que essa compreensão está situada no eixo Oralidade, no qual a modalidade oral da língua é o objeto de ensino priorizado, e conforme a citação, a anotaçáo escrita resulta da prática de escuta. Logo, não é a atividade principal, mas decorrente de uma situação oral.

Nesse sentido, corroborando o pensamento de Sautchuk (2003, p. 18), afirmamos "que a escrita não é um simples sistema de transcrição do oral, mas constitui um código completo e independente, que desenvolveu funções distintas e características de estruturação e de elaboração próprias".

A conceituação de escrita como uma língua que possui convençôes a serem obedecidas foi apreendida com base em uma das habilidades do eixo Conhecimentos linguísticos e gramaticais, a saber: "escrever, corretamente, obedecendo as convenções da língua escrita" (BRASIL, 2017, p. 131).

Desse modo, para escrever de forma correta é relevante o conhecimento e respeito às convenções da língua. Em razão disso, é necessário que as regras gramaticais sejam ensinadas visando o desenvolvimento da habilidade de escrita dos alunos.

\section{As CONCEPÇÓES DE ESCRITA NA BNCC: O QUE DIZEM OS TERMOS ANALISADOS?}

Os levantamentos do termo "escrita" e seus conceitos explícitos e implícitos permitem-nos compreender melhor a BNCC no que se refere à escrita nas séries finais do Ensino Fundamental, percebendo como o documento expóe esse objeto de ensino.

Sendo assim, apreendemos que na BNCC a escrita tem vários conceitos, como, por exemplo, uma forma de linguagem verbal, uma dimensão da língua, uma habilidade e um eixo que integra o componente Língua Portuguesa. Compreendemos também que na BNCC a escrita enquanto sistema alfabético refere-se diretamente aos Anos Iniciais do Ensino Fundamental, etapa em que a aprendizagem do código linguístico é extremamente necessária, pois possibilita o prosseguimento dos estudos e contribui para o desenvolvimento da escrita.

Com base nas análises dos conceitos explícitos e implícitos localizados na BNCC e respondendo ao primeiro objetivo específico - Indicar a(s) concepção(öes) de escrita presentes na BNCC -, constatamos que esse documento parametrizador está subsidiado pela concepção de escrita com foco na interação (cf. $\mathrm{KOCH}$; ELIAS, 2009), pois nas ocorrências do termo "escrita" notamos a relação direta entre escrita, a sua funcionalidade comunicativa e a consideração dos interlocutores. A prática de escrita também possibilita a participação no mundo letrado e a construção de novas aprendizagens.

Além disso, a concepção de escrita com foco na interação requer que o escritor ative conhecimentos (cf. KOCH; ELIAS, 2009) que possui para escrever bons textos. Isso é enfatizado pela BNCC quando este documento evidencia o conhecimento advindo 
do eixo Conhecimentos linguísticos e gramaticais acerca da norma-padrão como necessário à prática da escrita. Logo, quando a BNCC relaciona escrita à análise linguística e gramatical e, consequentemente, à ação de escrever corretamente seguindo as convençôes, está situando a relevância desses conhecimentos para o desenvolvimento da habilidade de escrita. Desse modo, não conhecê-los pode comprometer o processo de escrita quando esta se destina à publicação em esfera que exigem esse domínio.

Em relação ao segundo objetivo - Contribuir para a compreensão desse documento parametrizador -, acreditamos que conseguimos alcançá-lo ao identificar a concepção de escrita presente na BNCC, pois isso pode ajudar os leitores deste artigo a conhecê-la melhor, tendo em vista ser um documento recente, que precisa ser explorado pelos profissionais da educação.

Ademais, a utilização da terceira versão da BNCC nesta pesquisa pode ajudar o leitor a compreender o processo de elaboração do documento, conhecendo os saberes priorizados nas diferentes versóes e, com isso, se posicionar diante das orientações postas na versão homologada pelo CNE.

\section{WHICH WRITING ARE WE TALKING ABOUT? WRITING CONCEPTIONS AT BNCC}

\section{Abstract}

The National Curricular Common Base (hereinafter BNCC) is a normative parameter document that should be used in the elaboration of the curricula of public and private schools in Brazil. Thus, considering its relevance to education, the present article, resulting from a broader qualitative and quantitative research and of the documentary type, has the general objective of investigating the theoretical orientations present in the BNCC of Elementary School on writing teaching. In relation to the specific objectives, we have: (1) to indicate the writing conception(s) present in the BNCC, and (2) to contribute to the understanding of this parameterizing document. To carry out the analysis, we rely on the contributions of Kato (1986), Koch (2005), Koch and Elias (2009), Sautchuk (2003), among others. The results indicate that BNCC presents writing as an interaction activity.

Keywords: BNCC. Elementary School. Writing. Interaction.

\section{DE QUÉ ESCRITURA ESTAMOS HABLANDO? CONCEPCIÓN DE ESCRITURA EN BNCC}

\section{Resumen}

La Base Nacional Común Curricular (en adelante BNCC) es un documento parametrizador, de carácter normativo, que debe ser usado en la elaboración de los currículos de las escuelas públicas y privadas de Brasil. Por lo tanto, considerando su relevancia para la educación, el presente artículo, derivado de una investigación más amplia, de naturaleza cuantitativa y del tipo documental, tiene como objetivo general investigar las orientaciones teóricas presentes en la BNCC de la Enseñanza Fundamental sobre la enseñanza de la escritura. En relación con los objetivos específicos, tenemos: (1) indicar la (s) concepción (es) de la escritura presente (s) en la BNCC y (2) contribuir a la comprensión de este documento parametrizador. Para realizar el análisis nos apoyamos en las contribuciones de Kato (1986), Koch y Elias (2005; 2009), Sautchuk (2003), entre otros. Los resultados denotan que la 
BNCC presenta la escritura como una actividad de interacción.

Palabras clave: BNCC. Enseñanza fundamental. Escritura. Interacción.

\section{Notas}

A utilização da versão não homologada da BNCC se justifica porque a pesquisa foi desenvolvida antes da data de homologação pelo CNE, a saber: 20/12/17.

2 Este artigo foi produzido a partir da pesquisa de mestrado da primeira autora, na qual analisa a escrita na Base Nacional Comum Curricular (BNCC).

\section{REFERÊNCIAS}

BRASIL. Base Nacional Curricular Comum. Brasília: MEC/ SEB, 2017.

BRASIL. Lei de Diretrizes e Bases da Educação Nacional. De 20 de Dezembro de 1996. Disponível em: <http://www. planalto.gov.br/ccivil_03/Leis/L9394.htm>. Acesso em: 11 set. 2017.

FERREIRA, Elisa Cristina Amorim; LINO DE ARAÚJO, Denise. Desenvolvimento da escrita na academia: investigando o gênero resenha. In: SIMPÓSIO INTERNACIONAL DE LETRAS E LINGUÍSTICA, 3., 2013, Uberlândia. Anais... Uberlândia: EDUFU, 2013. p. 1-15.

GERALDI, João Wanderley. O texto na sala de aula. 4. ed. São Paulo: Ática, 2006.

GIL, Antonio Carlos. Métodos e técnicas de pesquisa social. 6. ed. São Paulo: Atlas, 2008.

KATO, Mary A. No mundo da escrita: uma perspectiva psicolinguística. São Paulo: Ática, 1986.

KOCH, Ingedore G. Villaça. Desvendando os segredos do texto. 4. ed. São Paulo: Cortez, 2005.

KOCH, Ingedore G. Villaça; ELIAS, Vanda Maria. Escrita e interação. In: . Ler e escrever: estratégias de produção textual. Sáo Paulo: Contexto, 2009. p. 31-52.

LE GOFF, Jacques. Documento-monumento. In: ENCICLOPÉDIA Einaudi. Memória-História, Portugal: Imprensa Nacional Casa Da Moeda, 1997. v. 1, p. 95-106.
NASCIMENTO, Antonio Naéliton do; LINO DE ARAÚJO, Denise. Transposição didática sobre o ensino de produção textual na BNCC. In: CONGRESSO DE INICIAÇÃO CIENTÍFICA DA UNIVERSIDADE FEDERAL DE CAMPINA GRANDE, 14., 2017.

SÁ-SILVA, Jackson Ronie; ALMEIDA, Cristóvão Domingos de; GUINDANI, Joel Felipe. Pesquisa documental: pistas teóricas e metodológicas. Revista Brasileira de História \& Ciências Sociais, São Leopoldo, ano 1, n. 1, p. 1-15, jul. 2009.

SAUTCHUK, Inez. A produção dialógica do texto escrito: um diálogo entre escritor e leitor interno. Sáo Paulo: Martins Fontes, 2003.

SOUZA, José Wellisten Abreu; FERRAZ, Monica Mano Trindade; COSTA, Thomaz Mariano Correia da. A significaçâo nos documentos parametrizadores nacionais: relação entre teorias e a prática nos livros didáticos. Joáo Pessoa, PB: UFPB, 2014.

Enviado em 10 de fevereiro de 2018

Aprovado em 18 de abril de 2018 